\title{
Élargir l'horizon de la dialectique des études culturelles au Québec : une critique de Fernand Dumont
}

\section{Jean-François Côté et Anouk Bélanger}

Numéro 47, janvier 2009

Dialogues théoriques sur la culture

URI : https://id.erudit.org/iderudit/1004984ar

DOI : https://doi.org/10.7202/1004984ar

Aller au sommaire du numéro

Éditeur(s)

Liber

ISSN

0831-1048 (imprimé)

1923-5771 (numérique)

Découvrir la revue

Citer cet article

Côté, J.-F. \& Bélanger, A. (2009). Élargir l'horizon de la dialectique des études culturelles au Québec : une critique de Fernand Dumont. Cahiers de recherche sociologique, (47), 143-171. https://doi.org/10.7202/1004984ar
Résumé de l'article

L'importance des études portant sur la culture peut se reconnaître aujourd'hui à la difficulté de définir un concept qui soit applicable autant aux manifestations mondiales du phénomène qu'aux saisies locales des pratiques donnant une forme spécifique à leur sens et leurs significations. En effet, alors que le mouvement de la mondialisation imprime à toute la planète des déterminations massives qui tendraient à homogénéiser les formes de sa réalisation, on rencontre partout également des éléments particuliers, voire singuliers, qui les prolongent ou les complètent, dans des voies parfois inattendues, ou encore qui contredisent ces déterminations, ou même qui semblent s'en abstraire, dissimulant alors la dialectique inhérente à toute forme symbolique impliquée dans le développement des sociétés humaines. La difficulté que pose l'étude de la culture aujourd'hui relève des possibilités de saisir cette dialectique inhérente au concept de culture pour en révéler les tenants et aboutissants dans des contextes autant mondiaux que locaux. C'est dans le cadre de cette problématique que nous réfléchissons ici à l'entreprise d'analyse de la culture au Québec proposée par Fernand Dumont. Cette critique réflexive d'une partie importante de l'œuvre de Dumont nous paraît nécessaire afin, d'une part, de montrer comment celle-ci participe d'un questionnement inachevé sur la culture et, d'autre part, de souligner comment cette œuvre appelle une réception qui soit à la hauteur des attentes de la réflexion contemporaine portant les pratiques culturelles, tout en sachant reconnaître les problèmes principaux qui apparaissent dans le contexte actuel de la réflexion. 


\section{Jean-François Côté et Anouk Bélanger Élargir l'horizon de la dialectique des études culturelles au Québec: une critique de Fernand Dumont}

L'importance des études sur la culture peut aujourd'hui se reconnaitre à la difficulté de définir un concept qui soit applicable autant aux manifestations mondiales du phénomène qu'aux saisies locales des pratiques donnant une forme spécifique à leur sens et leurs significations. En effet, alors que le mouvement de la mondialisation imprime à toute la planète des déterminations massives qui tendraient à homogénéiser les formes de sa réalisation, on rencontre partout, également, des éléments particuliers, voire singuliers, qui les prolongent ou les complètent dans des voies parfois inattendues, ou encore qui contredisent ces déterminations, ou même qui semblent s'en abstraire, dissimulant alors la dialectique inhérente à toute forme symbolique impliquée dans le développement des sociétés humaines. La difficulté que pose l'étude de la culture relève ainsi, à nos yeux, de cette possibilité de saisir cette dialectique pour en révéler les tenants et les aboutissants, afin de parvenir à interpréter activement le sens et la signification des formes culturelles qui ne cessent de poser des questions à l'observation, tant elles participent d'une dynamique qui intensifie toujours ses possibles contradictions ou ses possibilités nouvelles de médiation. Ainsi, à la présumée homogénéisation croissante d'une culture de masse mondialisée répondent les nouvelles hiérarchisations des pratiques et habitus de différents types de population, ainsi que des formes inédites d'expressions émanant d'horizons divers, alors qu'à la présumée particularité de certaines traditions culturelles, on retrouve en fait des croisements impliqués dans le dialogue des cultures, toujours au moins implicite lorsqu'on se met à la recherche des sources des pratiques humaines, qui procèdent toutes au fond d'un même fondement dans l'ordre du symbolique, et qu'on retrouve aux croisements de parcours si divers. 
C'est sur le fond de cette problématique que nous voudrions réfléchir ici à l'entreprise d'analyse de la culture au Québec proposée par Fernand Dumont, afin de montrer comment elle participe d'un questionnement inachevé sur la culture, fermé au surplus sur un horizon national incapable, d'une part, d'éclairer véritablement les sources d'une tradition culturelle spécifique et, d'autre part, d'articuler celle-ci aux phénomènes culturels contemporains susceptibles d'ouvrir une perspective plus large de participation à un projet mondial. L'enjeu de cette critique réflexive d'une partie importante de l'œuvre de Fernand Dumont nous paraît nécessaire afin de parvenir à lever l'une des impasses des études culturelles au Québec, en favorisant une démarche analytique plus ouverte à des comparaisons en provenance d'autres contextes que ceux issus directement d'ici, et en axant cette comparaison sur un dialogue critique avec d'autres orientations et traditions analytiques qui se sont penchées sur l'étude contemporaine de la culture. Pour ce faire, nous procéderons donc à une relecture de certaines analyses de Dumont, afin de pouvoir élargir l'horizon de la dialectique dans laquelle elles se meuvent. Nous procéderons d'abord par un examen du concept de culture tel qu'il est développé et utilisé chez Dumont. Nous ferons ensuite quelques comparaisons des analyses dumontiennes de la culture dans son contexte québécois avec d'autres contextes et d'autres approches, et terminerons enfin en proposant de nouvelles voies analytiques permettant d'entrevoir, selon nous, une étude renouvelée de la culture au Québec.

\section{Le concept de culture chez Fernand Dumont: un dédoublement problématique}

Le concept de culture occupe une place importante dans l'œuvre de Fernand Dumont; il s'agit en fait du cour de toute cette entreprise de réflexion, dont on peut retenir les deux ouvrages Le lieu de l'homme. La culture comme distance et mémoire (1968) et Le sort de la culture (1987) comme deux moments forts de cette conceptualisation ${ }^{1}$. Toute l'analyse de la société

1. Nous ne restreignons pas notre analyse, bien entendu, à ces deux seuls ouvrages, comme on le verra plus loin. Nous retenons comme source de référence les (Euvres complètes de Fernand Dumont, Québec, Presses de l'université Laval, 2008. En voulant voir un fil conducteur entre les deux ouvrages cités, ainsi qu'une filiation avec la problématique québécoise, nous nous opposons dans une certaine mesure à des interprétations comme celle de Danièle Letocha, pour qui Le lieu de l'homme constitue un ouvrage à considérer en relative abstraction de son lien avec l'horizon national de la réflexion dumontienne ("Entre le donné et le construit: le penseur de l'action. Sur une relecture du Lieu de l'homme", dans S. Langlois et Y. Martin (dir.), L'horizon de la culture. Hommage à Fernand Dumont, Québec, Presses de l'université Laval et Institut québécois de recherche sur la culture, 1995); nous nous y opposons entre autres parce que Dumont indique lui-même cet horizon à la fin de son livre en inscrivant ces thèmes qui deviendront si déterminants pour lui par la suite: «Pour l'heure, nous vivons encore dans l'entre-deux des traditionnelles 
québécoise que développe Dumont tient en fait au concept de culture qu'il met en avant dans (et dans l'intervalle entre) ces deux ouvrages, et la définition que plusieurs retiennent en général aujourd'hui de la culture québécoise doit souvent beaucoup à la formulation qu'il en a proposée, dans la foulée évidemment de nombreuses autres réflexions qui se développaient autour de la précision d'un enjeu national au sein de la Révolution tranquille et de son destin. Puisque la portée politique ou idéologique explicite du concept de culture est indissociable de sa portée épistémique, c'est sur cette dernière que nous voudrions d'abord nous attarder.

Dumont situe sa définition initiale de la culture au creux d'un espace, d'une distance, dédoublement ou déchirement, comme on voudra, entre "culture première" et "culture seconde". Cette séparation, qui parcourt à ses yeux toute formation culturelle, s'inscrit même en propre au sein de toute formation biographique personnelle (et au plus fort de sa propre autobiographie, comme il l'a rappelé dans Récit d'une émigration. Mémoires, dernier ouvrage publié de son vivant, en $1997^{2}$ ). Elle tient à une dynamique que Dumont n'explicite pas, mais qu'il constate à la suite de certaines études anthropologiques, ethnologiques et sociologiques du vingtième siècle qu'il suit, sans questionner plus avant cette idée ou sans vouloir en approfondir les conséquences logiques et épistémologiques, puisqu'il s'agit à ses yeux d'une donnée de base, inscrite dans sa facture contemporaine sous l'angle de la crise du langage: "La crise du langage nous a renvoyés à un dédoublement du monde et à un dédoublement de la culture. Même si nous n'avons commenté que quelques exemples, nous avons cru possible d'en tirer ce que nous pouvons considérer comme une observation de départ: la dualité de la culture est essentielle et commune aux formes diverses de sociétés; elle est particulièrement accentuée à notre époque, et c'est d'ailleurs pourquoi la crise de la parole est devenue le signe de toutes les

agglomérations de la durée et de la quête d'une nouvelle praxis sociale. Nous avons essayé de montrer que c'est là que se situe, pour l'essentiel, la crise de la culture actuelle: dans la recherche de médiations inédites entre le tissu quotidien de la vie et les objets culturels qui nous interrogent de leur magnifique distance, entre nos actions ordinaires et la science qui les remet en question. Si nous ne voulons nous perdre ni au-delà du poème ni dans les rets des pouvoirs les plus vils, il nous faudra une Politique. Et encore plus: une Mémoire. (F. Dumont, Euures complètes, op. cit., t. I, Le lieu de l'homme, p. 153; nous soulignons.) On sait quelle place les notions de "politique» et de "mémoire" tiendront dans la suite de l'œuvre de Dumont, et on verra comment leur ravalement à l'horizon québécois (ou plutôt canadienfrançais) scellera la limite de ses analyses.

2. F. Dumont, Euvres complètes, op. cit., t. v, Récit d'une émigration,p. 211-449. Rappelons l'ouverture de cette autobiographie, qui s'annonce ainsi: «Dans mon enfance et mon adolescence, j'ai connu ce que l'on dénomme la culture populaire. Le passage à l'école, à la science, m'aura laissé une persistante inquiętude dont j'ai fait problème d'école et de science. J'ai eu beau m'enfoncer plus avant dans les sentiers de l'abstraction, toujours il m'a semblé que j'abandonnais en route quelque question essentielle, que mon devoir était de ne pas laisser oublier ce que le savoir veut laisser à l'ombre sous prétexte d'éclairer le monde" (p. 215-216). 
autres. La dualité de la culture représente l'échappée et le lieu propre de la conscience par rapport au langage et au monde. Elle ouvre ainsi à une phénoménologie de l'Être que nous ne proposons pas de poursuivre pour elle-même. Nous sommes aussi invités à analyser les processus de dédoublement de la culture: c'est à cette dernière tâche que nous nous attaquerons. Si le champ de réflexion qu'elle délimite est moins exploré que les alentours immédiats de l'ontologie, il n'est pourtant pas d'un moindre intérêt philosophique ${ }^{3} . "$

On peut relever tout de suite que, sur le plan de la problématique de l'ontologie qu'elle évite sciemment de mettre en scène en contournant le problème d'une phénoménologie de l'Être, cette définition de la culture soustrait alors à sa propre entreprise la tâche de comprendre pourquoi et comment apparait la dynamique de dédoublement; elle sera donc aux prises avec une dialectique dont elle ignore les fondements, et ne pourra entrevoir de solution que dans le report indéfini de cette question du dédoublement elle-même, toujours assortie de cette "perte des origines", d'un côté, et d'une impossibilité de médiation ou de résolution, de l'autre ${ }^{4}$. En dehors de cette spécificité dans la manière dont il élude ainsi le problème fondamental auquel il se heurte, et sur lequel nous reviendrons sous peu, Dumont participe également d'un contexte de discussion plus large. Tel qu'il se positionne, il participe en effet d'un courant de pensée bien connu, tablant sur la reconnaissance d'une crise de la culture faisant suite à la décomposition de la culture bourgeoise et à l'émergence conséquente de la culture de masse, reconnaissance qui repose avant tout sur une vision «morale», comme l'ont souligné Patrick Brantlinger et Alan Swingewood, en montrant les versants positifs (Ortega Y Gasset) et négatifs (Arendt) de ce courant ${ }^{5}$. La réaction "romantique" à cette crise suscite alors une recherche des fondements qui

3. F. Dumont, Le lieu de l'homme, op. cit., p. 27 (nous soulignons).

4. Cette question, qui deviendra l'impasse sociologique du parti pris théologique de Dumont, apparaît d'ailleurs au tout début de son entreprise de réflexion et d'engagement intellectuel, comme le révèle Jean-Philippe Warren dans son étude de ses années de formation dont témoignent certains des premiers articles publiés de Dumont: «Finalement, conclut le jeune Dumont, "une seule voie nous est ouverte : celle de la mystique", c'est-à-dire celle d'une culture qui incarne "la tentation, chez l'homme, entre un Dieu perçu comme 'personne' et la réalité terrestre dont la science et l'action nous auront donné une conscience aiguë". Il faudra dans ce but édifier une culture dédoublée, où réalité concrète et spiritualité communiqueraient et échangeraient constamment, ce qui obligerait le chrétien à faire de sa vie "le continuel cheminement du monde à Dieu". L"édification de cette culture authentique cerne, avant même des recherches économiques, étatiques ou politiques, "le principal travail du chercheur chrétien" (J.-P. Warren, Un supplément d'âme. Les intentions primordiales de Fernand Dumont, Québec, Presses de l'université Laval, 1998, p. 129).

5. P. Brantlinger, Bread \& Circuses. Theory of Mass Culture as Social Decay, Ithaca (N.Y.), Cornell University Press, 1983; A. Swingewood, The Myth of Mass Culture, Atlantic Highlands (N. J.), Humanities Press International, 1977, entre autres p. 92-123. 
voudrait trouver en deçà de la modernité proprement dite les assises de cette perception morale, ce qui ouvre la porte à des recherches et des analyses susceptibles de comprendre, d'expliquer et d'interpréter les phénomènes culturels dans un contexte d'évolution et de transformation ".

L'observation de départ à laquelle se réfère Dumont est donc à situer dans ce contexte de réflexion, qui n'est pas neutre en soi - ou encore lié strictement à un horizon disons autobiographique -, mais procède bien de tout un héritage sociohistorique et culturel, d'un courant de réflexions et de débats ouverts qui sont ici passés sous silence. Cette mise en situation établie, Dumont s'attache ensuite à repérer des aires spécifiques de la "culture seconde" qui pourront faire l'objet d'une analyse plus détaillée?. Il écrit à ce sujet: «Il est plusieurs façons conventionnelles de désigner la dualité de la culture et d'en rendre compte. Elles exigent une petite exégèse préalable. La culture seconde se dégage d'abord de la culture commune par des procédés que nous engloberons dans le concept de stylisation. Par rapport à la perception et à l'action spontanées, le livre, le poème, le tableau représentent évidemment des décrochages et des reconstructions. Nous verrons d'ailleurs qu'il ne faut pas limiter à ces cas extrêmes un processus beaucoup plus général. Nous reconnaitrons aussi très vite l'antinomie de la stylisation et de la connaissance. Elle est manifeste à notre époque où nous opposons la science à l'art et où nous sommes même tentés d'exclure de la culture toute connaissance un peu technique. Avant d'être une nature que peuvent appréhender les stratégies objectives de la connaissance, le monde est d'abord, pour l'homme, un ensemble de significations. Si le dédoublement de la culture suppose une ouverture des configurations premières de la perception, la stylisation est toujours reconquête d'un sens du monde, tandis que la connaissance est la réduction de ce sens à des

6. On trouve aussi un bel exposé de tout ce mouvement de réflexion des deux cents dernières années chez J. Martín-Barbero, Des médias aux médiations. Communication, culture et hégémonie, Paris, CNRS, 2002, p. 25-147.

7. On en trouve évidemment d'autres formulations, comme celle qui ouvre par exemple Le lieu de l'homme: "En même temps que s'explicite la signification du monde dans une culture soucieuse de ses intentions et de ses fondements, la distance se fait plus nette entre elle et ce que, d'une manière confuse, on appelle la vie quotidienne. [...] S'il est, en définitive, quelque caractéristique essentielle de la culture actuelle, elle semble résider dans le sentiment d'un déchirement irréductible entre le monde du sens et celui des formes concrètes de l'existence. Dans l'espace dessiné par cette distance gravitent tout aussi bien les stratégies des organisations que les intentions de l'art et de la littérature. Faute de pouvoir se référer à quelques normes communes et explicites, les organisations doivent en fabriquer. De leur côté, les créateurs d'œuvres culturelles rêvent d'une genèse absolue des valeurs: astres incertains de leurs itinéraires, anticipations d'une réconciliation de l'homme et de l'univers indéfiniment différée" (op. cit., p. 3-4). Cette formulation a parfois varié, comme dans Le sort de la culture, où Dumont oppose également les expressions de "culture dispersée "et de "culture institutionnalisée " pour se référer à des réalités relativement équivalentes à celles qu'il désignait par "culture première" et "culture seconde". 
procédés de rationalisation et de calculs. La connaissance est donc un processus second par rapport à la stylisation, et nous ne l'aborderons qu'après elle. En troisième lieu, les ensembles de la culture seconde, les humanismes explicites, sont disjoints de la culture commune par des mécanismes qui relèvent de la disparité des groupes et des hiérarchies sociales. C'est bien ce que suggèrent des expressions courantes comme "culture aristocratique", "culture populaire" ou "culture de masse". Il faudra ici donner toute sa portée à cette différenciation des groupes et ne pas la ramener simplement à des facteurs extérieurs à la culture, comme on le fait souvent, par exemple à propos des inégalités de la fréquentation scolaire selon les classes sociales. C'est la nature même de la culture qui est ici aussi en jeu. [...] La stylisation, la connaissance et la participation sociale sont trois vues premières des choses qu'il sera utile d'épouser tour à tour, mais sans les opposer rigidement ${ }^{8}$."

On voit donc bien comment sont posés ici les problèmes d'une analytique de la culture, qui répartit ainsi des aires distinctes, mais en fonction de critères relativement ambigus; au sein même de la "culture seconde", on doit ainsi comprendre que l'on retrouve tout aussi bien les arts et les sciences (distingués à leur tour dans leurs visées respectives) que les différentes formes de cultures qui peuvent apparaitre et se différencier à leur tour sur le plan historique, en rapport à des critères cette fois issus de catégorisations davantage sociales que proprement épistémiques. Les problèmes que pose cette répartition préalable sont dès lors considérables: qu'est-ce qui permet d'envisager par exemple que les sciences ou les arts partagent avec la culture populaire ou la culture de masse une appartenance à la "culture seconde", mais qu'ils demeurent malgré tout distincts de ces dernières "par des mécanismes qui relèvent de la disparité des groupes et des hiérarchies sociales"? Ne sont-ce pas précisément de tels mécanismes qui, sur le plan sociohistorique, produisent des distinctions épistémiques? Ou encore, comment peut-on considérer, à l'inverse, les rapports entre la "culture aristocratique" et le développement des arts et des sciences, dans le procès de la modernité européenne, par exemple? Ou même: est-il permis d'envisager, de ce point de vue, des rapports qui uniraient les arts et la "culture populaire» ou la "culture de masse"?

D'un point de vue épistémologique, on voit bien que les définitions proposées par Dumont posent quelques problèmes, qui dériveront inévitablement dans les analyses qu'il développera de chacun de ces domaines - nous y reviendrons plus loin. Retenons ici cependant que, d'un bout à l'autre de ses réflexions sur la culture, Dumont maintiendra ces ambiguïtés et que, plus fondamentalement, celles-ci entraineront des confusions sur le plan des diagnostics posés à l'égard de la définition des aires de la pratique culturelle, ainsi que sur ses fondements ${ }^{9}$. Comme nous

8. F. Dumont, Le lieu de l'homme, op. cit., p. 27-28.

9. Citons un passage du Sort de la culture: «De la plus modeste parole aux œuvres de la culture seconde, de ceux-ci aux idéologies de la culture savante, la 
reviendrons dans la prochaine section sur cette question de l'analytique des aires culturelles, nous dirons ici un mot sur la question des fondements de cette analyse dumontienne.

La problématique générale dans laquelle s’inscrit Dumont, de manière explicite par endroits mais le plus souvent de manière implicite, est celle des "sciences de la culture" depuis la fin du dix-neuvième siècle; il s'agit en effet pour elles de tenter d'assurer un horizon de théorisation et un programme analytique qui soient propres aux sciences humaines et qui traversent en somme toutes les disciplines qui s'y rattachent - de la psychologie, ou même de la psychanalyse, à l'histoire, de l'anthropologie à la science politique, de la linguistique à la philosophie et, bien entendu, à la sociologie. Ce n'est donc pas un hasard si les références et les dialogues qu'entretient Dumont avec les auteurs qu'il aborde dans ses ouvrages rassemblent en fait à un point ou à un autre toutes ces disciplines, sans pour auțant, la plupart du temps, assumer la tâche d'un débat précis à l'égard d'un auteur ou d'un autre, ou même à l'intérieur d'une seule discipline. Or la problématique des sciences de la culture s'est, en particuliẹr depuis Rickert, Dilthey, Weber et Simmel, concentrée sur la question du sens et

culture tout entière serait traversée par un déplacement de la référence qui, du monde, se replierait vers la culture. Sans doute, les paroles, le langage, le poème, la théorie de la relativité font appel aux choses; sans quoi, ils me seraient inintelligibles. Mais ils deviennent à leur tour des choses, qui me sont autant repères que cette réalité à laquelle m'ont accoutumé ma vie quotidienne et les conventions de ma société. C'est pourquoi nous sommes devenus capables de parler de la culture comme d'une entité : en dédoublant le monde et les procédés par lesquels nous l'interprétons, en faisant de l'interprétation un monde en soi. La culture comme horizon, comme naissance d'une nouvelle histoire, emprunterait de là sa possibilité et son emprise. Tenant ferme à cette hypothèse, $j$ 'en reviens à cette organisation sociale de la culture seconde qui m'avait déjà retenu mais que nous verrons maintenant sous un jour nouveau. Ce que j'appelais des cercles de cultures, ne serait-ce point des milieux particuliers où la référence à la culture s'est déprise de la référence au monde? L'agora des Grecs, les universités médiévales, les réseaux de relations des humanistes de la Renaissance, la chambre du père Mersenne ou les collèges des jésuites, la Royal Society ou l'Académie des sciences, les écoles de littérature ou de peinture, le laboratoire ou l'observatoire: la recension serait infinie et elle ne devrait pas manquer de souligner les différences de conditions de temps et de sociétés. Elle offrirait une phénoménologie de ce processus par lequel, de la société plus vaste, on est arrivé à des sociétés plus restreintes, où le monde est apparu différent parce que l'on portait moins le regard sur lui que sur la manière de l'appréhender" (Eurres complètes, op. cit., t. II, p. 447). On devrait commenter en détail ce passage, qui encore une fois fait l'impasse sur la problématique d'une "culture première" associée directement ici au monde, et mème au monde en soi (sans médiation? sans intervention symbolique? sans signification construite? sans sens?), et qui compare le développement de différentes aires de "culture seconde" à des "rétrécissements" du monde - ce qui apparaît pour le moins paradoxal, puisque, au contraire bien sûr, le monde de la science (pour ne rien dire du monde des différentes théologies...) vise clairement au contraire à un "élargissement ", ou en fait à une universalité de sens et de signification. 
de la signification des pratiques culturelles pour en tirer un programme analytique distinct de celui des sciences naturelles ${ }^{10}$ en procédant de la place centrale donnée à la question de l'interprétation - de là le croisement fondamental de la réflexion dumontienne avec l'herméneutique, comme l'a reconnu Serge Cantin ${ }^{11}$. Cela a permis notamment aux sciences de la culture, chez des auteurs comme Ernst Cassirer, Mikhail Bakhtine ou Michel Freitag (pour ne rien dire de Lévi-Strauss, Lacan ou Foucault), de même qu'au courant issu des travaux de Raymond Williams et, surtout, du programme des cultural studies, de tirer parti d'une analytique des formes symboliques en fonction de la reconnaissance du caractère dialectique de leur genèse, de leur formation et de leur transformation ${ }^{12}$. En fait, cela tient précisément au fondement de cette problématique dans une ontologie dialectique, plus ou moins ouvertement reconnue par chacun de ces auteurs dans l'héritage, assumé de manière diverse par chacun d'eux (dans la contestation ou dans le prolongement), de la philosophie hégélienne qui en a la première posé les bases et dont le marxisme, le fonctionnalisme, le structuralisme et même le poststructuralisme ont poursuivi les enjeux de diverses façons, en fonction de programmes analytiques relativement différents. Chez Dumont, ces enjeux ont été en quelque sorte court-circuités par l'adhésion d'une réflexion à un horizon plutôt théologique; de là le blocage à l'égard d'une "phénoménologie de l'Être", tel que nous l'avons souligné, et de là aussi certains amalgames d'aires culturelles distinctes dans les analyses produites par Dumont, en particulier celles visant la culture au sein de la société québécoise, constamment ramenée à une tradition dans laquelle seront idéalement réunies l'Église et la Cité ${ }^{13}$. Revenons donc à ce

10. Si l'on excepte les emprunts sporadiques à la biologie - comme chez Durkheim, Parsons ou Luhmann, avec les concepts de fonction ou de système, ou encore chez Bourdieu, avec le concept de champ - ou aux mathématiques emprunts constants dans la sociologie quantitative, notamment.

11. S. Cantin, "Une herméneutique critique de la culture", dans S. Langlois et Y. Martin (dir.), op. cit., p. 47-64. Nous différons ici du diagnostic posé par Cantin à l'égard des rapports de Dumont à la problématique de l'herméneutique propre aux sciences humaines. Le rapprochement trop étroit fait avec la théologie situe la position dumontienne dans "cette dialectique de la critique et de l'espérance comme ressort de la culture occidentale" (ibid., p. 62).

12. Voir notamment à ce sujet A. Mattelart et E. Neveu, "Cultural Studies' Stories: la domestication d'une pensée sauvage?", Réseaux, n 80, 1996 (<http:// enssibal.enssib.fr/autres-sites/reseaux-cnet/80/01-matte.pdf $>$ ); A. Mattelart et E. Neveu, Introduction aux Cultural Studies, Paris, La Découverte, 2003; P. Brantlinger, Crusoe's Footprints, Londres, Routledge, 1990; I. Davies, Cultural Studies and Beyond. Fragments and Empire, Londres, Routledge, 1995.

13. Encore une fois, nous insistons sur la très grande constance de la réflexion dumontienne qui ne se trahit pas d'un ouvrage à l'autre; sur cette question du fondement de la réflexion, qui rejoint autant la question ontologique que le programme analytique des sciences de la culture dans la perspective de la philosophie de l'histoire, citons ces passages de L'anthropologie en l'absence de l'homme: "Nous sommes donc amené à une constatation de fond: il s'est produit un processus d'idéa- 
point à la question de la distinction possible des aires culturelles, toujours selon les visées analytiques ouvertes par une ontologie dialectique qui voit dans les formes symboliques un travail incessant de distinction dans la formation et la transformation des expressions culturelles.

\section{Les aires culturelles et les études culturelles contemporaines: l'exemple de la culture populaire}

Comme nous l'avons déjà souligné, la distinction analytique entre "culture première" et "culture seconde" demeure fortement problématique chez Dumont, et cette difficulté s'accroît dès lors qu'est posée la distinction ultérieure des différentes aires culturelles où se déploient des pratiques spécifiques, selon des formes qu'il convient de reconnaitre. Car dès le moment où la culture ("seconde" mais, paradoxalement, pas "première"...) est conçue comme déchirement, tout le programme analytique semble engagé dans

lisation de l'objet historique semblable à celui que Husserl a reconnu dans les sciences de la nature et qui comporte les mêmes conséquences. Les philosophies de l'histoire, nous y avons déjà insisté, ont joué à cet égard un rôle capital. En supprimant l'assise concrète de celui qui interprète l'histoire — la Cité, l'Église... que pouvaient-elles lui substituer d'autre que le moi singulier de l'interprète, des groupements relatifs ou le devenir abstrait de la raison? Sans support historique un peu assuré, l'historien contemporain ne cède pas nécessairement aux rapides synthèses des philosophies de l'histoire, mais sa liberté est analogue à la leur: il peut projeter sur les témoignages et les indices divers que fournit le passé des modèles, des types idéaux indéfiniment diversifiés. Lesté de son propre poids historique, sa situation étant devenue hypothétique, il procède à une idéalisation de l'histoire pareille à celle que poursuivent les sciences de la nature. [...] Husserl s'est cru obligé de parier sur un télos de la Raison qui nous viendrait d'une histoire abstraite. Ce qui était pour le moins contradictoire: une tradition ne peut pas être abstraite. Husserl proposait d'en revenir au commencement, que l'originaire devienne la tâche philosophique. [...] On peut se demander si cet absolu, ce double absolu faudrait-il dire plutôt, ne ressemble pas par quelque côté à l'idéalisation de la science où Husserl voyait par ailleurs la crise même de la science en tant que crise de la culture. En voulant revenir au commencement,'n'est-ce pas cette science-là dont Husserl cherche les origines, restant par là enfermé dans les termes mêmes du problème qu'il dénonce? Alors qu'il s'agissait des fondements d'une culture. Et pour les cultures, il n'y a pas de commencement qu'une philosophie pourrait reprendre. La culture est médiation. On ne commence pas une médiation, on la reconnait." ( Euvres complètes, op. cit., t. II, p. 161 et 169). On voit donc comment est réaffirmé ici le postulat de base de Dumont, en même temps qu'est posé l'insurmontable problème, à ses yeux, du travail dialectique au sein des médiations symboliques. Sa critique de Husserl, entreprise sous l'angle de l'abstraction à laquelle elle consent, apparait dans ce sens tout à fait étrange: Husserl n'entreprenait-il pas d'en revenir aux sources de la rationalité occidentale (sous l'angle de sa "réduction" phénoménologique, bien entendu, mais néanmoins en fonction de son ancrage sociohistorique concret dans une tradition explicite, celle de la pensée grecque, puis plus largement celle du rationalisme occidental - qu'on se rappelle les études sur l'origine de la géométrie)? 
une tentative de réparation et animé d'une nostalgie de réconciliation à travers la recherche d'une source primaire de constitution de croyances ou de valeurs communes. Ainsi, dans sa définition de la culture populaire, Dumont reprend à nouveau le principe fondamental qu'il défend, en écrivant: "D'abord, et je n'aurai plus à insister là-dessus [...], la culture populaire est une construction par la culture savante qui, du même mouvement, s'édifie elle-même. La culture savante a ceci de singulier qu'elle est une représentation de la culture. La culture barbare, sauvage, populaire est son opposé, pour mieux dire son résidu: elle peut donc être son objet ${ }^{14}$."

Le parti pris de Dumont concernant une telle séparation qui établit la culture populaire comme un objet de réflexion pour la culture savante est bien sûr discutable, puisqu'il procède, comme on l'a noté, d'une genèse sociohistorique, reportée ici sans plus de questionnement sur le plan épistémique; en réaffirmant cette distance plutôt qu'en questionnant ses origines, Dumont table donc sur un présupposé qui évacue toute possibilité de considérer la récupération de l'expérience vécue en fonction de sa réflexivité inhérente, de ses possibilités de développement et des représentations qu'elle génère et qui constituent le domaine du sens et de la signification une attitude éthique et épistémologique que Raymond Williams, par exemple, va disqualifier justement parce qu'elle empêche systématiquement la reconnaissance de toute dimension "ordinaire" de la culture ${ }^{15}$. Ce parti pris aura également le désavantage de susciter une attention à l'égard de la culture populaire et de la culture de masse fortement teintée de misérabilisme ou de populisme, deux postures qui génèrent au fond la même condescendance, comme l'ont déjà fait remarquer Jean-Claude Passeron et Claude Grignon ${ }^{16}$. Mais ce sont là des écueils que ne perçoit pas Dumont, et qui l'entraînent plus avant dans une théorisation encore plus problématique, prenant même l'allure d'une impasse.

Une fois posée cette définition, Dumont constate en effet que "[1]a culture populaire d'aujourd'hui, dans l'ère des sociétés dites de masse, n'est

14. F. Dumont, Le sort de la culture, op. cit., p. 426.

15. R. Williams, "Culture is ordinary", dans The Raymond Williams Reader, Londres, Blackwell, 2001, p. 10-24. Ce petit texte de Williams datant de 1958, à saveur autobiographique en ce qu'il met en scène notamment le "contact initial" de ce fils de paysans avec la culture savante anglaise de Cambridge, est d'autant plus instructif quand on le compare à la manière dont Dumont entrevoit lui-même son propre déchirement par rapport à ses origines familiales modestes. Chez Williams, contrairement à ce que l'on trouve chez Dumont, pas de déchirement, mais plutôt une reconnaissance du fondement essentiel des valeurs culturelles dans cette "culture première" (pour employer l'expression dumontienne) qui permet de mieux l'assumer, de manière plus critique, dans ses prolongements ultérieurs que sont les connaissances et acquis de la "culture seconde". Il s'agit donc d'une tout autre façon d'assumer l'héritage de la "culture populaire", qui a l'avantage surtout de ne pas la perdre de vue. D'une manière corollaire, il s'agit aussi d'une position éthique qui aura des résonances épistémiques - encore une fois opposées à celles de Dumont.

16. C. Grignon et J.-C. Passeron, Le savant et le populaire, Paris, Seuil, 1989. 
pas tout à fait identique à la culture traditionnelle [mais que] néanmoins, par beaucoup de traits fondamentaux, la culture populaire contemporaine ressemble à la culture traditionnelle". L'analogie proposée ici, au demeurant assez surprenante, entre la culture populaire contemporaine et la culture traditionnelle, tient au fait que, au sein de celles-ci, on ne trouverait pas de dissociation entre pratique et culture, et qu'elles fonctionneraient donc toutes deux dans un horizon de "culture première" dans laquelle sont immergés les individus. Cette perspective reste d'autant plus étonnante que Dumont reconnaît par exemple que "[1]a croissance des médias de masse a joué un rôle décisif dans la désintégration de la culture traditionnelle", mais parvient tout de même à réaffirmer, et cela à titre hypothétique, une perspective analytique selon laquelle «la culture populaire y serait considérée, en un premier temps tout au moins, comme un avatar de la culture traditionnelle ${ }^{17}$ \%. On reconnait bien ici le réflexe dumontien qui, craignant semble-t-il plus que toute autre chose les ruptures dans l'ordre de la signification et du sens - et conséquemment dans le domaine épistémique -, essaie de les colmater ou de les suturer avant même d'avoir réussi à en tirer une réflexion susceptible de conduire à la reconnaissance de formes symboliques inédites marquant une histoire faite d'autre chose justement que d'une simple reproduction. Ce réflexe, entre autres, et au-delà des problèmes qu'il parvient ainsi à masquer, prive en quelque sorte toute expression culturelle de la créativité (de la pö̈èis) qui lui est inhérente, en l'obligeant à se soumettre à des formes qu'elle ne doit ou ne peut que reproduire, sous peine de ne pas être reconnue comme appartenant de plein droit au domaine de la culture "légitime»"

L'enjeu analytique qui se dévoile ici apparaît comme une constante des réflexions sur la culture contemporaine depuis au moins la deuxième

17. F. Dumont, Le sort de la culture, op. cit., p. 426-427. Il nous faut en effet souligner ici l'incohérence de l'argumentation, puisque si l'on suit la logique annoncée au départ, c'est bien la culture bourgeoise moderne qui procédera la première à la "désintégration" de la culture traditionnelle - à moins bien sûr de considérer la culture bourgeoise comme une culture traditionnelle (ce qui est relativement gênant d'un point de vue sociohistorique et épistémique), ou encore d'oblitérer le sens de la culture bourgeoise, ce qui apparaîtra en fait comme la position de Dumont dans Chantiers. Essais sur la pratique des sciences de l'homme (1973), lorsqu'il insiste pour situer l'«exception socio-historique" de la société québécoise qui, à travers l'historiographie produite par François-Xavier Garneau, aurait "transmué, sans apparente césure, la conscience bourgeoise de son temps en conscience nationale» (CEuvres complètes, op. cit., t. I, p. 484; nous soulignons). Voir également à ce sujet J.-F. Côté, "Compte rendu de Fernand Dumont, Chantiers. Essais sur la pratique des sciences de l'homme", Recherches sociographiques, vol. 42, no 2, 2001, p. 372-377.

18. Les jugements précoces de Dumont à l'égard de la culture de masse et de la culture ouvrière, rapportés par la lecture que fait Jean-Philippe Warren d'articles publiés au tout début des années 1950, restent à cet égard éclairants. Résumant et citant Dumont, Warren écrit: «Sans assise intérieure pour une véritable vie spirituelle ou même intellectuelle, que peut l'ouvrier? Il se délègue, de façon pathologique, dans des vies imaginaires populacières. [...] L'ouvrier se satisfera des pacotilles 
moitié du vingtième siècle (si l'on excepte certaines avancées plus précoces de l'école de Francfort, chez Walter Benjamin notamment, ou de l'école de Chicago, chez Robert E. Park), moment où l'essor spectaculaire des médias de communication, en particulier la télévision, traverse tout l'horizon de la culture occidentale. Cet enjeu avait suscité l'attention de Raymond Williams dès la fin des années 1950 , et la manière dont il entrevoyait le développement d'une analytique de ce croisement entre la culture et les médias le portait à envisager une toute nouvelle appréhension de la dynamique de formation et de transformation de la culture. Chez lui, et en fonction d'une distinction établie entre culture idéale (associée à lá poursuite de valeurs universelles), culture vécue (associée à toute période historique d'une société) et culture documentée (associée au choix et à la sélection établis envers des cultures vécues, mais passées), l'analyse de la culture prend appui autant sur le présent que sur le passé ou l'avenir, mais cela en fonction précisément des modalités distinctes de ses expressions ${ }^{19}$. Les principes d'une telle analytique débouchent sur la reconnaissance d'une compréhension méthodologique de la répartition topologique de strates

de la culture de masse, il ne cherchera pas dans ses temps de loisirs à assouvir sa nostalgie de l'Être et des valeurs. Au lieu de se recueillir auprès du prêtre et d'y trouver une solution à ses angoisses, au lieu de profiter de la lecture des grands écrivains, l'“admiration principale des foules" converge vers des stars "plongées dans l'immoralité, l'insignifiance ou le sentimentalisme bébête". Les chrétiens ne peuvent s'empêcher de s'intéresser au drame de ces prolétaires à qui est refusé l'accès à une véritable culture" (J.-P. Warren, op. cit., p. 128). De cette attitude "édifiante" aux jugements ultérieurs, on voit que la position de Dumont n'aurait pas évolué énormément - sinon dans son vocabulaire... Le contraste avec la pensée de Raymond Williams est de nouveau frappant: chez ce dernier, l'expression "culture is ordinary " conteste autant une compréhension de la culture populaire d'où est évacué un potentiel de créativité qu'une définition de la culture savante ou artistique comme lieu où la routine, la répétition mécanique n'existerait pas, et donc la conjonction à laquelle il fait appel n'est pas la réconciliation entre culture première et culture seconde, mais est plutôt comprise comme "une manière d'explorer une emphase alternative, de découvrir un point de vue au sein de ce territoire complexe, d'où l'on pourrait tenter de parler d'une culture commune, ou (l'expression me semble différente maintenant) d'une culture en commun. En rapport avec cette emphase se trouve la proposition que la culture est ordinaire: qu'il n'y a pas de classe spéciale ou de groupes impliqués dans la création des significations et des valeurs, soit dans un sens général ou dans des domaines spécifiques d'arts ou de croyances. Une telle création ne pourrait pas être réservée à une minorité, si douée qu'elle fût, et ne lui était pas, même en pratique, réservée... En parlant de culture commune, on disait donc que, premièrement, la culture était la façon de vivre des gens, ainsi que les contributions vitales et indispensables de certaines personnes spécifiquement douées - comme manière de critiquer cette culture divisée et fragmentée que nous avons maintenant" ( $\mathrm{R}$. Williams, Resources of Hope, cité dans P. Jones, Raymond Williams' Sociology of Culture, Londres, MacMillan, 2006 [2004], p. 3).

19. Voir entre autres R. Williams, The Long Revolution, New York, Harper \& Row Publishers, 1961, p. 41-71, et Culture and Society, Londres, Random House, 1993 [1958]. 
culturelles où, comme l'a posé Jesús Martín-Barbero en suivant Williams, on retrouve l' "archaïque", le "résiduel» et l'«émergent", qui correspondent respectivement aux éléments passés, persistants et nouveaux des formes culturelles $^{21}$. On voit donc aisément le rapprochement que l'on peut établir ici avec l'entreprise de Dumont (où se retrouvent également le "résidu " ou le "résiduel", associés à la persistance de la culture traditionnelle), mais on remarque aussitôt que Williams, lui, reconnait également de l' archaïque» et de l' "émergent» qui ne peuvent être tout simplement confondus avec la persistance d'une culture dominante, sans que l'on perde de vue ce qui, dans l'unité présumée de cette dernière, serait à la fois - mais distinctement de l'ordre du passé et du nouveau. La portée de cette comparaison s'éclaire évidemment dans les remarques de Williams concernant le développement de la culture documentée, qui porte bien sûr sur la reconstruction de la culture vécue (celle que Dumont appelle "culture première") dans un contexte sociohistorique différent: à cause du fait qu'elle procède d'un choix, celui-ci est constitué par toutes sortes d'intérêts, notamment des intérêts de classe ou des intérêts idéologiques dominants ${ }^{21}$. En d'autres termes, la tradition culturelle est toujours, dans ce cas, une tradition sélective qui peut très bien choisir de considérer du "dominant " comme un

20. Voir à ce sujet l'exposé de la place de ces catégories développées par Williams et leur rôle dans tout le développement de la réflexion dans le débat entre "peuple" et "masse", dans J. Martín-Barbero, op. cit., p. 90-91. Martín-Barbero introduit la notion d' "archaïque", là où Williams préférait soutenir un trait inhérent à la culture dominante vis-à-vis duquel le "résidurel» offrait des possibilités d'alternative ou de contestation par rapport à cette culture dominante.

21. Williams écrit: "La tradition sélective crée ainsi, à un niveau, une culture humaine générale; à un autre niveau, la mémoire historique d'une société particulière; à un troisiène niveau, plus difficile à accepter et à vérifier, un rejet d'aires considérables de ce qui était auparavant une culture vivante. Dans une société donnée, la sélection sera opérée par plusieurs sortes d'intérêts particuliers, incluant des intérèts de classe. Tout comme la situation sociale présente va largement opérer la sélection contemporaine, le développement de la société, le procès du changement historique, déterminera largement la tradition sélective. La culture traditionnelle d'une société tendra toujours à correspondre à son système contemporain d'intérêts et de valeurs, car elle n'est pas constituée d'un ensemble d'œuvres absolues mais de sélections et d'interprétations. En théorie, et dans une mesure limitée en pratique, les institutions qui sont formellement désignées pour garder en vie la tradition (en particulier les institutions d'éducation et de savoir) sont dédiées à la tradition en entier, et pas à une certaine sélection à l'intérieur de celle-ci en fonction d'intérêts contemporains. L'importance de cette tâche est très grande, puisque l'on voit constamment, dans le travail de la tradition sélective, des renversements et des re-découvertes, des retours à des ouvres apparemment laissées pour mortes, et clairement cela n'est possible que s'il y a des institutions dont le rôle est de garder de grandes aires de la culture passée, sinon vivantes, du moins disponibles. Il est naturel et inévitable que la tradition sélective suive les lignes d'évolution d'une société, mais parce que cette évolution est complexe et continue, la pertinence d'œuvres passées, dans quelque situation future que ce soit, est imprévisible" (R. Willians, The Long Revolution, op. cit., p. 51-52). 
«résiduel» — ou d'assimiler, dans un autre sens, de l'«archaïque» ou de l'"émergent" au "résiduel". Voilà qui décrit précisément l'opération analytique à laquelle procède Dumont dans ses vues sur la culture populaire, comme on vient de le voir. Si ce n'est pas tant du côté du repérage idéologique ou politique de cette opération que nous logeons notre présente lecture de Dumont, il n'y a pas de doute que celle-ci devrait éventuellement être analysée pour ce qu'elle est, ou interrogée en tout cas dans le sens des intérêts qu'elle défend, sous le couvert de son appréhension de la tradition culturelle québécoise, perçue et interprétée en fonction de l'homogénéité présumée de sa composition canadienne-française. Nous nous contentons pour notre part de nous interroger ici sur la sélection opérée dans la constitution de la culture traditionnelle, afin de saisir ce qui reste dans l'ombre de cet éclairage que Dumont veut jeter sur la reproduction contemporaine de la culture à laquelle il participe. Car c'est bien cette reproduction qui est à l'œuvre au sein de la continuité présumée de la culture traditionnelle dans la culture populaire, puisque cette dernière se nourrit de ce que Dumont appelle des résidus et des transpositions de la première. Au-delà même de cette opposition primaire, Dumont reconnaît dans la culture contemporaine d'autres phénomènes qu'il voit à l'œuvre dans le travail de distinction des formes, mais qu'il s'empêche tout autant de considérer dans leurs significations contradictoires: "Il n'en demeure pas moins qu'une zone intermédiaire s'est constituée où des individus de plus en plus nombreux sont à cheval sur la bourgeoisie et la classe ouvrière. Pour les qualifier, on parle de classes moyennes. L'expression est vague et insatisfaisante; le phénomène qu'elle désigne est pourtant réel. Par le revenu, par l'habitat, par les relations sociales, par les intermariages, des ingénieurs ou des cadres, des enseignants ou des employés de bureau se retrouvent dans des genres de vie semblables, consomment les mêmes produits culturels, fréquentent les mêmes associations. La culture populaire ne se dissout pas plus que la culture bourgeoise dans ce mélange. Peut-être même en profite-t-elle pour s'étendre et se fortifier. Il ne serait pas étonnant que la culture populaire, loin de s'étendre peu à peu comme on le prétend de divers côtés, connaisse une nouvelle mutation après toutes celles du passé. Son affrontement avec des sources qui ne viennent pas d'elle, sa faculté de les assimiler n'auraient rien d'inédit ou de surprenant ${ }^{22}$."

Sans que l'on sache donc tout à fait à quel sort est vouée, sur le plan analytique, la culture populaire dans ce contexte - sinon dans celui qui fait dire à Dumont que "nos travaux sur la culture populaire ne sauraient être isolés des investigations d'ensemble sur la culture [et que] rien ne serait plus stérile que d'en faire une spécialitée ${ }^{23}{ }$ —, nous sommes donc laissés dans une position qui trahit de nouveau non seulement de l'ambivalence ou des ambiguités, mais bien plutôt de la confusion ${ }^{24}$. Cette confusion était déjà à l'origine d'une première thématisation de la culture de masse présente dans

22. F. Dumont, Le sort de la culture, op. cit., p. 428-429.

23. Ibid., p. 430. 
Le lieu de l'homme, et nous y revenons brièvement ici pour marquer d'abord une certaine évolution dans sa compréhension, puis le brouillage de la spécificité dans laquelle la maintiendra Dumont, l'empêchant par le fait même de reconnaitre la nouveauté des formes émergentes des expressions culturelles dans ce domaine et les significations dont elles sont porteuses ${ }^{25}$. Cela permettra à l'analyse dumontienne de privilégier, après cette

24. En conclusion de cette partie de son ouvrage portant sur la culture populaire, et comme dans une réponse implicite aux remarques de Williams concernant la constitution de.la "tradition sélective", Dumont écrit: "L'alternance de la nostalgie et de la récupération du peuple, dont j'évoquais les figures anciennes, ne cesse point de nous inspirer. Il ne suffira pas d'éclairer les facettes de ces idéologies, de dénoncer leurs ressources de rationalisation à l'usage de la culture savante, des intellectuels, des partis et des mouvements sociaux. Il faudra opposer systématiquement les deux versants d'institutions et de modes d'expression: savoir de l'ingénieur et savoir ouvrier, école et apprentissage non officiel, religion savante et religion populaire, organisation bureaucratique et liens communautaires... Cet inmense travail est commencé. Il ne constituera pas seulement une nouvelle étape de la culture savante et de sa parente, la culture bourgeoise. À condition de garder à l'horizon de notre investigation une grande question, la plus déconcertante, à laquelle il n'est point encore possible de répondre: comment la recherche sur la culture populaire pourrait-elle provenir aussi de cette culture elle-même?» (ibid., p. 430). On voit ici, dans cette question ultime maintenue ouverte par Dumont, la contradiction insoluble dans laquelle sa propre entreprise d'analyse et de théorisation l'a mené.

25. Conformément à son idée de ne pas faire de la culture populaire un "objet spécialisé", Dumont livrait, dạns Raisons communes (1995), une des demières réflexions qu'il consacra à cette question, tiraillée encore par un diagnostic similaire à ce qu'on a vu jusqu'ici: "Nous avons quitté l'ancienne culture; nous n'en avons pas édifié une autre qui soit à la portée du peuple. La culture populaire risque en effet de devenir un souvenir. [...] Quel sens pouvait revêtir pour nous ce recours à un monde qui n'est plus le nôtre? Il se peut que ce passé ait eu valeur d'avenir; le reporter en avant faisait lever d'autres images que la logique toute plate de certains gérants de la Révolution tranquille. Nous regardons tour à tour en avant et en arrière; parviendrons-nous à démêler la nostalgie d'avec la mémoire? [...] II reste que la culture ne se fait pas à partir du vide, puisqu'elle est le travail collectif grâce auquel les hommes tissent leurs liens avec le monde. La culture a une dimension politique, parce que la quête de soi n'est pas dissociable de la quête commune. S'il ne faut pas pleurer les choses mortes, ne point fouiller désespérément dans nos souvenirs, comment se garder de jeter sur l'avenir un regard abstrait, de prolonger en utopie un projet de culture qui ne serait que l'improvisation et la justification d'une classe récemment émancipée? Construction d'une Cité politique, édification d'une culture, renouveau d'une démocratie sociale: ces trois tâches se rejoignent dans la même quête de raisons communes" (CEuvres complètes, op. cit., t. III, p. 574). Il faudrait donc montrer, à partir d'ici, comment la question sociologique se transfonme en question politique chez Dumont, sans que sa définition fondamentale soit éclaircie - ou, pour le dire autrement, que dans ce passage continuent de persister les problèmes que nous soulignons, qui effectueront ainsi un saut, de problèmes à caractère épistémique (qu'ils sont) à des problèmes à caractère idéologique (qu'ils deviennent). 
disqualification première du sens de la nouveauté au sein des expressions émergentes, un repli sur des éléments « résiduels» qui deviendront les seuls garants de la tradition culturelle - mais en étant considérés alors comme des "archaïsmes" ou des "transpositions", marquant le signe de la permanence de cette tradition culturelle, et non des transformations véritables qui l'affectent pourtant. Dumont écrit ainsi: «Le mythe ancien était la forme la plus haute de la référence à la tradition. Sa permanence était sa garantie: c'est par là que, comme une sorte d'archétype, il inspirait les comportements. L'univers imaginaire de la culture de masse domine aussi la vie quotidienne, mais ce n'est pas par son ancienneté: tout comme l'information, il doit sans cesse donner le sentiment de la nouveauté. Il n'en est pas, pour cela, tout à fait discontinu, étalé comme des fragments de temps disparates. Pour qu'il soit porteur de sens, il lui faut une certaine cohésion et une résistance à la durée. Il y parvient, non pas comme le mythe ancien en se situant dans une sorte de temps originaire distinct du temps des hommes, mais par la stéréotypie incessante des situations et des actions dont il donne la représentation. C'est par cette absence de structure stable que la mythique actuelle peut rejoindre la fluence de la vie privée. En un sens, elle est effectivement plus proche de la vie quotidienne que le mythe ancien; elle la domine moins aussi. [...] Mais cette proximité des idéaux est, pour chacun d'entre nous, le signe même de leur précaritée ${ }^{26}$."

La critique amorcée ici du sẹns que portent en elles les expressions de la culture de masse soutenues par les médias s'établit à partir du fait qu'il s'agit en somme d'une culture fabriquée et non pas spontanée. On doit donc relever au passage que Dumont considère à ce moment la culture de masse comme "culture seconde" et non comme "culture première" (ce qu'il a tendance à faire, comme nous l'avons vu, lorsqu'il revient sur la question dans Le sort de la culture). En dépit de cette difficulté supplémentaire, son analyse se poursuit dans la critique de la forme organisée, cette fois, des expressions contemporaines: "Travail et consommation peuvent donc être considérés comme des lieux d'élaboration de la nouvelle culture. Dans l'un et l'autre cas, l'organisation est la contestation de la culture comme a priori et, plus encore, elle s'y substitue comme cohérence et comme densité de l'empirisme. La culture resurgit comme exigence et souvent comme sous-produit de l'organisation; elle ne descend plus sur l'existence comme un avènement préalable à nos conduites. [...] Ce que la culture de jadis proposait comme un accord traditionnel et unanime sur les formes du désir est maintenant fabriqué. Les valeurs sont davantage le moteur que la fin de l'organisation; c'est leur efficacité qui est d'abord retenue. D'où une prodigieuse illusion. Nous avons le sentiment exaltant d'être libre, et infiniment plus que l'homme de la tradition. Nous pouvons élire nos intentions et faire jouer, dans des options et ces refus, les infinies possibilités de notre moi. Mais ce sont là des jeux solitaires en marge de l'histoire. [...] Dans nos sociétés, comme dans celle de jadis, la culture tend à

26. Ibid., p. 124. 
se constituer comme une vision du monde explicite à l'horizon de l'ensemble des individus. Mais cette totalité de la culture seconde se présente aujourd'hui comme un ensemble de possibles abstraits ${ }^{27}$."

Il y aurait évidemment plusieurs choses à commenter dans ce passage. Nous nous contenterons de souligner celles qui, d'un point de vue analytique, apparaissent comme des impasses dans la considération de l'expression culturelle. D'abord, il faut bien sûr mentionner que réapparaît ici le problème de la distinction entre "culture première" et "culture seconde", mais sous un jour qui trouble définitivement et irrémédiablement toute possibilité réelle de compréhension, d'explication et d'interprétation de ce dont il est question. Comment présumer en effet que la "culture première" repose sur un "accord traditionnel et unanime"? Sinon à la ranger dans l'ordre du mythe, mais qui est déjà en lui-même, comme l'ont montré entre autres les analyses d'Ernst Cassirer, de Claude Lévi-Strauss et de Michel Freitag, la solution imaginaire qu'ont trouvée les cultures primitives et traditionnelles à leurs propres conflits et contradictions de sens et de signification $^{28}$ ? Comment ne pas voir également que, même sous la gouverne autoritaire de l'Église et du régime féodal, au sein de la société traditionnelle européenne du Moyen Âge et des débuts de la Renaissance, se déploie une culture populaire vivante qui contredit et travestit précisément cet autoritarisme en parvenant à formuler ses résistances et ses oppositions dans des formes expressives typiques - tel le rire, ou tel le carnaval, comme l'a si bien montré Mikhail Bakhtine ${ }^{29}$ - déstabilisant et inversant les significations pour montrer la facticité et le travail plastique, dialectique de l'ordre monolithique qui paraitrait s'imposer? Comment ne pas voir que le développement de la modernité, dans les termes de l'établissement d'institutions politiques, appelle nécessairement et, au-delà de la constitution concurrente d'une entité unifiée sur la base du peuple ou de la nation, suppose inévitablement l'établissement de rapports de domination, ainsi que les modalités diverses et opposées de médiations idéologiques susceptibles de masquer ces contradictions en créant une pluralité d'expressions représentant des positions plus ou moins antagonistes ${ }^{3(i)}$ ? Comment, par la suite, considérer l'inanité des expressions culturelles qui seraient

27. F. Dumont, Le lieu de l'homme, op. cit., p. 107-108 (nous soulignons).

28. E. Cassirer, Langage et mythe, Paris, Minuit, 1973, p. 110-111, et Essai sur l'homme, Paris, Minuit, 1975, p. 112; C. Lévi-Strauss, Anthropologie structurale, Paris, Plon, 1958, et La pensée sauvage, Paris, Plon, 1962; M. Freitag, Dialectique et société, vol. 2, Culture, pouvoir, contrôle. Les modes de reproduction formels de la société, Montréal et Lausanne, Saint-Martin et L'Âge d'homme, 1986, p. 113-130.

29. M. Bakhtine, L'ouvre de François Rabelais et la culture populaire au Moyen Age et sous la Renaissance, Paris, Gallimard, 1970. Voir également à ce sujet comment André Belleau analyse la signification d'une partie importante de la création romanesque québécoise contemporaine, dans son intégration de la tradition populaire du rire et du carnaval (Notre Rabelais, Montréal, Boréal, 1990, p. 141-156).

30. De nouveau, nous renvoyons ici à M. Freitag, op. cit., p. 287-310. 
produites ou organisées dans une perspective en marge de l'histoire, comme un ensemble de possibles abstraits, alors que c'est au contraire tout le sens et la signification des expressions culturelles contemporaines qui passent nécessairement par de nouveaux types de médiation, comme n'ont eu de cesse de le montrer les analyses de la culture contemporaine de Georg Simmel, de Raymond Williams, de Néstor García Canclini ou d'autres ${ }^{31}$ ?

Ce sont de telles questions qui surgissent à la lecture de la sociologie de la culture qu'a développée Fernand Dumont, et qui appellent aujourd'hui des réponses complètement différentes de celles qu'il a voulu donner. On peut en effet considérer, une fois que l'on a constaté les difficultés, les ambivalences, les ambiguités, les contradictions et les impasses de ses analyses, que la perception qu'il a développée de la culture (et de la société québécoise) demeure à tout le moins partielle, et certainement partiale, dans l'évaluation qu'elle fait des expressions qu'elle rencontre et de l'évolution dont elle veut rendre compte. C'est de ce point de vue que nous contestons donc l'autorité que l'œuvre dumontienne a acquise dans le domaine de l'analyse culturelle ${ }^{32}$. Elle ne nous semble pas correspondre aux possibilités analytiques véritables qui sont offertes par tout le champ de l'expression culturelle contemporaine, qui inclut évidemment tout regard analytique que l'on porte sur le passé, comme sur le présent, tout autant que les ouvertures sur l'avenir ${ }^{33}$. C'est à partir de là que nous pouvons entrevoir d'autres

31. G. Simmel, Philosophie de la modernité, Paris, Payot, 2005 [1989]; R. Williams, The Long Revolution, op. cit., et Culture and Society, op. cit.; N. García Canclini, Transforming Modernity. Popular Culture in Mexico, Austin, University of Texas Press, 1993, et Hybrid Cultures. Strategies for Entering and Leaving Modernity, Minneapolis, University of Minnesota Press, 1995.

32. Nous parlons ici d'«autorité" en fonction non seulement de l'œuvre écrite de Dumont, qui continue de nourrir des réflexions qui se situent dans son aval - souvent sans faire la critique nécessaire dans sa réception-; mais aussi en fonction du pouvoir réel qu'a exercé Fernand Dumont dans sa vie, en tant que professeur, intellectuel et figure marquante de la Révolution tranquille et de la sociologie québécoise, aussi bien que comme sous-ministre adjoint au ministère de l'État du Développement culturel (1977-1978) et président et directeur scientifique de l'Institut de recherche sur la culture (1979-1990), entre autres, comme le révèle sa biographie.

33. Dans le diagnostic qu'ils portaient sur l'état du développement de la recherche sur la culture au Québec en 1985, Fernand Dumont et Fernand Harvey écrivaient: "L'histoire de la culture québécoise et des études qui ont porté sur elle depuis 1960 se ramène à la défection de la référence. Dans cette défection, les investigations scientifiques ont trouvé le vide propice à leur essor; en retour, ce vide, elles ont contribué à l'élargir et elles ont tenté de le combler à leur façon. Cette défection de la référence, il est aisé d'en repérer sommairement les avatars. [...] La Révolution dite "tranquille" s'est voulue une rupture. Et pour s'en assurer, à l'exemple de bien du monde, les scientifiques ont tenté de le démontrer. La conscience historique est devenue "malheureuse", pour employer avec un peu d'humour le mot célèbre de Hegel. De ce malheur procède la plus grande portion de la production idéologique et scientifique des vingt dernières années" 
possibilités analytiques, davantage susceptibles de parvenir à rendre compte de la vitalité de la culture, en montrant notamment comment les expressions culturelles contiennent une dynamique proprement dialectique qui les porte au travers de leurs mises en forme (leur in-formation), de leurs déformations et leurs transformations, à partir des conditions sociohistoriques qui leur sont propres, et en fonction des possibilités qu'elles rencontrent, de leurs possibles contradictions et médiations inédites qu'elles offrent. Nous voudrions donc donner une idée de la direction de telles analyses, toujours en montrant comment ces nouvelles voies analytiques se distancient de la problématique dumontienne et de ses applications aux analyses de la culture au Québec ${ }^{34}$.

\section{De nouvelles voies analytiques pour les études culturelles au Québec}

Si nous reprenons ici la question des transformations de la culture populaire en rapport avec les développements de la culture de masse, nous pouvons

(F. Dumont et F. Harvey, «La recherche sur la culture», Recherches sociographiques, vol. 25, nos 1-2, 1985, p. 86-87). Nous soulignons ici le caractère consternant du jugement porté par Dumont et Harvey, en relevant tout autant l'utilisation étrange de l'expression "conscience malheureuse" pour qualifier l'esprit du développement positif du mouvement de réflexion et d'analyse de la culture qu'ils examinent. En effet, cette expression peut sans doute être appliquée à toute réflexion qui entrevoit le fossé entre ses réalisations et l'idéal qu'elle sait exister tout en sachant ne pouvoir jamais l'atteindre (comme souvent dans le cas de la conscience religieuse, par exemple), mais ne peut pas être appliquée aux courants positivistes de plusieurs recherches auxquelles Dumont et Harvey se réfèrent (même en dépit de la naïveté relative dans laquelle évoluent ces courants...). Or ce jugement s'accorde avec les visées qu'eux-mêmes entretiennent à l'égard de ce qu'ils appellent une "science de la culture québécoise" (ibid., p. 117) - dont on se demande par ailleurs si elle désigne une science "de la culture québécoise" (ce qui serait assez curieux), ou alors une "science québécoise" de la culture (ce qui est tout aussi... spécial). Ils écrivent ainsi : "De notre culture, on a beaucoup parlé depuis vingt ans; des essais, des polémiques se sont multipliés; les uns et les autres ont été suggestifs; mais le souci d'une préoccupation d'ensemble n'a pas, à notre sentiment, pénétré intimement la recherche scientifique. [...] Sans doute, des théories ont pénétré chacun de ces domaines: le fonctionnalisme, le marxisme, la sémiologie, etc., ont partout circulé et selon des modes successives. Mais cela n'aura pas pernis que se dégage à partir de l'objet étudié, la culture québécoise, un débat serré qui eût pu influencer efficacement la recherche empirique et, par voie de retour, le développement d'une science de la culture" (ibid.).

34. Dans ce qui suit, nous traiterons de différentes voies de théorisation qui font une bonne place à des traditions de pensée et des écoles (anglaise, allemande) dont Dumont a très peu parlé. Dans l'évaluation qu'il faisait d'une partie de ces travaux, Guy Rocher y voyait un complément à l'approche dumontienne; nous axons davantage notre évaluation sur une confrontation plus directe entre les apports de ces travaux et les carences que nous décelons chez Dumont. Voir G. Rocher, "La sociologie anglo-saxonne de la culture: aperçus sur une évolution récente ", dans S. Langlois et Y. Martin (dir.), op. cit., p. 361-372. 
montrer comment le jeu des formes symboliques traduit une dynamique qui impose des déplacements de sens et de signification dont on doit impérativement tenir compte pour établir comment s'opère la transmission culturelle. Et si l'on tient ici à montrer l'emprise d'éléments "résiduels» au sein de l'expression culturelle contemporaine, ce ne peut être qu'en examinant la forme qu'ils prennent dans ce contexte, en relevant justement que cette forme détermine essentiellement le contenu de ce qui est véhiculé.

Cette dynamique est au cœur de la dialectique de la culture car elle procède d'une activation du fondement même de l'ordre du symbolique, qui produit des conflits, contradictions, croisements, métissages, relations ambiguës, au fil des processus d'interprétation, tablant sur des sources de créativité, de récupération ou de neutralisation. Le terrain de ces dynamiques, au terme desquelles sont produites des pratiques et des formes culturelles, ne peut pas être assimilé à un simple terrain de réconciliation, pas plus qu'il n'est le champ aplani de toute possibilite de reproduction de sens et de signification également pertinente et significative. La culture s'y présente autant sous la forme de la contestation sourde ou ouverte que de l'approbation implicite ou explicite, bref des tendances opposées de la médiation qui participent des processus historiques de (re)construction de sens.

Dans le domaine télévisuel, par exemple, nombre de productions se sont manifestées qui ont fait un retour sur l'histoire ou la tradition culturelle francophone du Québec, et souvent avec une popularité certaine - que l'on pense à des téléromans tels Les belles histoires des pays d'en haut (diffusé dans les années 1950 et 1960 et ayant pour cadre la fin du dix-neuvième siècle), Les filles de Caleb (diffusé au début des années 1990 et se situant au tournant du dix-neuvième siècle) ou encore Le temps d'une paix (diffusé au début des années 1980 et dont l'intrigue se déroulait dans la période de l'entre-deux-guerres). S'il est clair dans tous ces cas que la vraisemblance de ce qui est représenté à l'écran tient à des éléments qui ressemblent à des aspects sociohistoriques des situations, il est tout aussi clair que la mise en forme traduit des impératifs qui sont complètement assujettis aux exigences de la télédiffusion, et par conséquent parfaitement étrangers au contexte de référence, le formatage ne renvoyant ainsi à ses référents supposés que d'une façon au mieux iconique que permettent les techniques et les technologies de reproduction, alors que leur symbolique loge complètement ailleurs ne serait-ce que par l'activité télévisuelle qui s'insère dans une "quotidienneté familiale", comme l'appelle Jesús Martín-Barbero, structurée de façon totalement autre que le contexte auquel elle se réfère ${ }^{35}$. Tout ce qui tient à la composition de la forme est, en d'autres termes, à situer du côté de l'intérêt contemporain que la culture de masse entretient vis-à-vis des possibilités de reproduction de formes culturelles à travers sa diffusion -

35. J. Martín-Barbero, op. cit., p. 177-205. Cela est aussi vrai des téléromans qui tablent sur d'autres aspects plus contemporains de la vie sociale. Aussi, à l'exemple du téléroman pourraient bien entendu être substitués le film ou d'autres types de production tels que le roman. 
comme l'avait déjà saisi Walter Benjamin, qui l'assimilait toutefois (trop) rapidement au déclin de l'"aura" de l'œuvre d'art - , correspondant aux dispositions culturelles présentes de ceux qui fabriquent ces produits tout autant que de ceux qui les consomment. Nous arrivons ainsi aux considérations esthétiques, idéologiques et même éthiques qui déterminent ces productions et qui les insèrent dans des circuits de distribution spécifiques. Du point de vue du rapport au passé ou à la tradition culturelle, l' "actualisation" qui est en cause en est donc une qui prescrit essentiellement la transformation des formes culturelles; comment pourrait-il en être autrement, si l'on tient compte justement du fait que la société qui a vu ces transformations s'opérer en elle s'est par la même occasion transmuée d'une époque à une autre? Si, par exemple, certaines émissions donnent lieu à un tel engouement qu'elles en deviennent des cultes - en ce qu'elles sont suivies par un public important qui adhère «religieusement» à leur diffusion régulière -, ne faut-il pas voir justement là une nouvelle forme de "religiosité" propre aux sociétés actuelles ${ }^{36}$ ? Et celle-ci n'est-elle pas, d'ailleurs, plus active que les formes de pratiques religieuses qui ont été contestées puis abandonnées, au Québec, dans les mêmes années et dans le cours d'une Révolution tranquille qui annonçait la profondeur des bouleversements en cours dans les mours, les pratiques et les formes de développement de la culture? C'est en tout cas ce qui motivait Pierre Maheu à encourager au milieu des années 1960 le développement d'une attitude Ti-Pop à l'égard de cette culture passée, attitude susceptible à ses yeux de parvenir à la juste évaluation d'une tradition culturelle ayant un besoin pressant de s'actualiser dans des formes complètement nouvelles et

36. Ne faudrait-il pas en effet interpréter de cette façon le jugement de Dumont lorsqu'il écrit que, «[a]u Québec, la culture religieuse se cherche désormais au ras du sol "? Bien qu'il soit évident que ce n'est pas là le sens qu'il accorde aux possibilités de la transmission d'un héritage religieux (dont il est prêt, par ailleurs, à croire qu'il s'est transposé dans l'ordre du politique au moment de la Révolution tranquille...). Notre suggestion peut paraitre audacieuse, mais qu'on lise la suite de ce jugement dumontien en ayant en tête cette possibilité : "Une société ne persiste en son devenir que par le dédoublement de son être empirique et de son être symbolique, qu'en trouvant dans son inachèvement ce qui à la fois la ramène à elle-même et la déroute devant une image de soi qui la dépasse. Une telle société échappe à la tentation de manipuler les personnes comme des objets, et les groupes comme des mécanismes. Cette conscience de soi, déchirée si elle se veut authentique, ce n'est pas fatalement une religion qui l'insuffle. Mais cette conscience n'en est pas moins à la hauteur de la conscience religieuse" (Le sort de la culture, op. cit., p. 530). Rappelons qu'à ce titre, Durkheim caractérisait le phénomène religieux essentiellement par le biais du culte et de l'effervescence sociale entourant les activités de pratique s'y référant, et non en rapport au contenu strictement théologique censé l'habiter, opposant ainsi la compréhension sociologique à l'appréhension essentialiste ou dogmatique du phénomène. Mais c'est exactement sur ce point que Dumont entretient des réticences par rapport à l'approche durkheimienne, comme il le mentionne explicitement dans Récit d'une émigration, op. cit., p. 317-318. 
inédites, souvent irrévérencieuses à son égard, sous peine de sombrer dans le simple horizon d'un folklore ne parvenant plus à exprimer une signification autre que muséale. Le Ti-Pop parvenait ainsi à généraliser un jugement esthétique par rapport à la culture québécoise dans les termes de son expérience concrète du monde actuel. Dans les termes de Maheu: "Qu'est-ce donc que le Ti-Pop? Eh bien, le Ti, c'est le Québec, comme dans "Chez Ti-Jean Snack Bar", "Ti-Lou Antiques", ou tout simplement comme dans "Allo, ti-cul". Et le Pop, c'est si on veut le Pop Art. Mais il ne s'agit pas spécialement d'art. C'est plutôt de culture qu'il s'agit - notre vieille culture, qui se mérite bien le titre de Culture Ti-Pop... À la fois nostalgie et sarcasme, ironie et bonheur, retrouvailles et rupture, l'attitude Ti-Pop, qui transforme les objets sacrés en objets de conscience esthétique, les rend profanes, est donc une attitude profanatrice. Ti-Pop, c'est une démarche paradoxale qui consiste à assumer un certain passé national, mais à l'assumer comme passé justement, c'est-à-dire à le poser du même coup comme dépassé [...]. Mais entre le Canada français dépassé et le Québec à inventer, il faut une démarche qui fasse le joint. Joual, Ti-Pop ou ce qu'on voudra, l'histoire de cette métamorphose que doit être notre révolution culturelle passera par la période du cocon, ni chenille ni papillon, à la fois négation et affirmation, moment paradoxal d'une mise au monde qui est aussi bien une mise à mort. Ou bien nous réussirons cela, ou bien le problème du Québec se réglera tout seul et nos petits-enfants seront des Américains. Ce n'est qu'en se transformant de fond en comble que la culture québécoise ne sera pas tout à fait dévalorisée dans le monde des voyages interplanétaires. Et inversement, ce n'est qu'en assumant notre origine dans ce monde périmé que nous nous donnerons à nous-mêmes et à nos idées le poids de réalité nécessaire pour vaincre l'inertie qui maintient encore le Québec dans la culture d'un autre âge ${ }^{37}$."

Cette désignation de Ti-Pop parvenait donc à rendre compte d'un jugement à l'égard de ce passé dégagé de tout pessimisme, en l'assimilant à la vie des formes expressives et aux possibilités élargies de leur transformation ${ }^{38}$. Que la thématisation du Ti-Pop soit apparue au travers de la réflexion d'un intellectuel et qu'elle ait été également associée au mouvement artistique du Pop art, dans les années 1960 au Québec, n'empêche ainsi nullement qu'elle ait été assumée et avalisée dans le contexte plus élargi de productions culturelles au sein de la production télévisuelle,

37. P. Maheu, "Laïcité 1966", Parti Pris, vol. 4, no 1, 1966, p. 73-75.

38. Ce dont le Refus global avait déjà annoncé les couleurs dans le domaine artistique une vingtaine d'années auparavant, en ouvrant officiellement la voie aux expérimentations modernistes. Il est à cet égard particulièrement frappant que Fernand Dumont, fût-il attentif au développement culturel de la société québécoise, ait complètement laissé dans l'ombre de ses analyses toute espèce de référence à ce mouvement important du Refus global. Comme s'il avait préféré demeurer justement en retrait par rapport au modernisme, en restant enfermé dans les limites du romantisme - qui avait pourtant, dans la chronologie qu'on peut en faire, pavé la voie au modernisme dès la deuxième moitié du dix-neuvième siècle. 
notamment - et cela même si la teneur de la critique qu'elle contenait à l'égard de la tradition culturelle a pu varier d'un contexte à l'autre. Que l'on songe au téléroman La p'tite vie, diffusé de 1993 à 1999, dans lequel les références traditionnelles et contemporaines de la culture subissaient un "re-brassage" ironique et parodique aigu. Au travers d'une dynamique familiale traditionnelle revue sur un mode plutôt délirant, c'est tout l'univers de la quotidienneté qui prend ici une tournure obsessive et maladive, dans laquelle ne pénètre aucun repère susceptible de sortir de cette aliénation, sinon pour en souligner l'absurdité totale. L'horizon caricatural des références culturelles traditionnelles invoquées est ici porté à un niveau de bouffonnerie qui réjouit le public actuel, qui lui se reconnaît également dans certains de ces travers ataviques.

D'un autre point de vue, de telles productions télévisuelles, bien qu'elles appartiennent incontestablement au domaine de la culture de masse, excluent-elles pour autant des liens avec la culture "cultivée", comme l'entrevoyait la société moderne bourgeoise? Dans la mesure en effet où elles impliquent des auteurs (souvent romanciers), de même que des acteurs, réalisateurs, techniciens, etc., il semble, bien au contraire, qu'elles rejoignent toutes sortes de populations, et, au surplus, un public qu'on peut croire tout aussi composite. De quelle manière interviennentelles alors vis-à-vis de la culture traditionnelle, sinon en l'enrichissant de développements qui feront en sorte de prolonger la tradition culturelle en la transformant par le biais de nouvelles déterminations? Ces déterminations sont d'ailleurs à entrevoir également dans la perspective où le média télévisuel lui-même s'inscrit dans un contexte sociétal contemporain qui traverse aujourd'hui toutes les sociétés dans le monde. Ainsi, la particularité de la télévision québécoise devrait être plutôt comprise en fonction de cet horizon auquel elle participe et non pas, à l'inverse, comme une réalité à saisir en premier lieu comme "distorsion" d'une culture nationale, tel que le conçoit par endroits Dumont ${ }^{39}$. Son propre horizon de diffusion est d'ailleurs à la mesure de limites qui ne sont pas strictement nationales, ni d'ailleurs québécoises, comme on le voit par exemple dans les publics canadiens et internationaux de la francophonie qu'elle rejoint ${ }^{41}$.

39. “Une culture déjà séparée des pratiques quotidiennes favorisait l'accès à des messages, à des modes, à des mythologies fabriqués industriellement. Déracinés de leur univers, dépourvus de genres de vie un peu assurés de leurs durées, les habitants des banlieues cossues ou des taudis de la basse-ville étaient prêts à accueillir une culture venue de loin et élaborée pour de vastes espaces. Les gens ont reçu une information couvrant une aire infiniment plus large que celle de leur existence. Cette information a pris couleur mythologique. Elle fait de l'univers humain un bric-à-brac de représentations" (Le sort de la culture, op. cit., p. 363-364).

40. Comme le note Roger de la Garde: «La télévision telle qu'elle est constituée aujourd'hui par les pratiques discursives des chercheurs, des professionnels, des critiques, des politiciens et des propriétaires a toujours voulu être une télévision nationale, rassembleuse du plus grand nombre de semblables, qu'ils soient représentatifs de la nation canadienne-française, de la société québécoise, d'un marché 
Cette perspective analytique rejoint en fait certaines analyses contemporaines qui ont montré comment les séparations usuelles des aires culturelles, et particulièrement peut-être celles qui ont marqué le développement de la modernité (dans l'opposition de la culture bourgeoise et de la culture populaire, ou de la culture moderne et de la culture traditionnelle), sont aujourd'hui à réévaluer dans leur portée significative. Néstor García Canclini a ainsi insisté pour montrer comment le croisement contemporain des aires de production traditionnelles, modernes et postmodernes pouvait être judicieusement appréhendé en fonction de la formation de cultures hybrides, qui témoignent autant des formations culturelles que de leurs transformations contemporaines ${ }^{41}$. L'avantage que l'on tire d'une telle perspective est qu'elle nous permet de concevoir une évolution des formes culturelles qui inclut vraiment les possibilités de significations auxquelles se rapportent les pratiques à l'intérieur d'une société — dans un sens similaire à ce que Raymond Williams avait proposé en se référant aux catégories du "persistant" ou du "dominant", du "résiduel " et de l' "émergeant» — en fonction de l'appréhension du développement sociohistorique qui nous conduit à la société actuelle, au Québec comme ailleurs dans le monde.

Une telle perspective permet également de considérer la culture populaire en fonction de la créativité qui lui est inhérente - une prérogative que la modernité, comme la culture traditionnelle du reste, tendait à reléguer aux marges des développements plus légitimes de la culture officielle. Mais dans ce registre, l'ouvrage Subculture: The Meaning of Style, de Dick Hebdige, a montré tout ce que le phénomène des modes et des styles se développant au sein des jeunes générations comportait de rapports différenciés et contestataires à l'égard de la culture officielle; la vie culturelle, dans ce sens, témoigne des mouvements qui alimentent les transformations non seulement esthétiques mais aussi éthiques dans l'ordre social ${ }^{42}$, Et si le

culturel nord-américain de langue française [...]. Cette télévision a pris forme au sein d'une conjoncture où se trouvaient réunis, à l'échelle du Québec historique des années 1940 et 1950, des facteurs d'ordre social, technologique, historique, culturel, géopolitique et créatif, d'une part, et des débats collectifs autour de l'émergence d'une nouvelle identité nationale, d'autre part. De tout cela a émergé une télévision québécoise dans la continuité d'une histoire du développement des médias au Québec, mais aussi dans la rupture qui est indissociable de toutes les pratiques sociales et culturelles qui l'ont accueillie" ( $R$. de la Garde, "De la télévision à la vision télé", dans D. Lemieux et al. (dir.), Traité de la culture, Québec, Institut québécois de recherche sur la culture, 2002, p. 915.

41. N. García Canclini, Hybrid Cultures. Strategies for Entering and Leaving Modemity, op. cit.

42. D. Hebdige, Subculture: The Meaning of Style, Londres, Routledge, 1987. Dans cet ouvrage, Hebdige parvient à synthétiser toute une tradition d'études sur la ville et le style de vie (comme en a produites l'école de Chicago, par exemple) en relançant sous cet angle, au sein des cultural studics de Birmingham, la thématique de la contestation. Le style devient ainsi le lieu où se construit la contestation sociale, de la même façon que la thématique des identités en général en viendra à être conçue, par exemple chez D. Chaney (Lifestyles, Londres, Routledge, 1996). 
renvoi à la nature apparemment si superficielle du phénomène de la mode, par exemple, n'apparaît pas porteur de significations dignes d'être rapportées dans l'horizon de l'analyse sociologique, n'est-ce pas parce que cette dernière se rend alors aveugle à cette "figure de la vie", comme l'appelle Georg Simmel, en soutenant que, dans ces créations, "la finalité sociale et individuelle a objectivé les courants opposés de la vie pour leur donner les mêmes droits ${ }^{43}$ "? On voit ainsi, au contraire, comment l'expression culturelle reste toujours sensible aux mouvements de la signification et du sens, qui surgissent justement des tensions et contradictions de la vie sociale dans des formes qui paraissent parvenir à en incarner les médiations, selon des degrés divers, et en rapport aux courants plus ou moins éphémères qui les déterminent. C'est en cela notamment que la culture réfléchit sa vie propre.

En suivant de telles voies analytiques dans les études sur la culture, nous sommes donc appelés à revenir également sur des jugements d'ensemble portés à l'égard du développement culturel des sociétés contemporaines, dont le Québec renvoie un écho à la fois particulier et exemplaire. La spécificité du développement culturel de la société québécoise ne peut être assimilée à un cas d'espèce qui n'aurait pas d'équivalent dans le monde. Au contraire, c'est plutôt la manière dont ces mouvements mondiaux se réfléchissent dans la culture d'ici qui appelle la réflexion à se pencher sur les caractéristiques des formes culturelles qui se constituent en fonction de conditions dialectiques spécifiques. Et il y a davantage, ici, qu'une simple question de principe, puisque c'est en fait de notre capacité d'évaluer l'expérience du monde au creux d'expériences spécifiques qu'il s'agit - au lieu que cela soit, à l'inverse, la recherche d'une "transcendance» par rapport à cette expérience qu'il faudrait localiser. Encore ici, la démarche dumontienne apparaît comme un repoussoir nous permettant de dégager ces conditions de leurs limites prescrites a priori, pour ainsi dire, dans un destin qu'on dirait scellé de toute éternité ou dans une historicité "bloquée». Car à vouloir restreindre les vues sur la tradition culturelle à un espace-temps sociohistorique qui en a donné une expression particulière - qui loge chez Dumont, comme on le sait, dans l'expression de l'historiographie canadienne-française naissant chez François-Xavier Garneau dans les années 1840 - l'analyse court-circuite toute autre possibilité de reconnaissance de ce qui participe de l'évolution active de la culture ${ }^{+4}$. Ainsi, lorsque Dumont s'intéresse à ce qu'il appelle des "hypothèses excessives", qui ne pourraient apparaître "qu'au prix d'une mutation de la conscience, d'une mutation de la culture susceptibles de donner à la tradition un nouveau visage", il ne parvient justement pas à dépasser cet horizon de réflexion dans lequel se conjuguent le formalisme

43. G. Simmel, op. cit., p. 150.

44. Cette idée, qui nait explicitement en 1973 dans Chantiers, parcourt toute la suite de l'œuvre de Dumont; elle est entre autres réaffirmée avec force dans L'avenir de la mémoire (Cuvres complètes, op. cit., t. II, p. 596). 
vide d'un espoir de réinterprétation, demeurant un simple væu pieux, et le pessimisme réaffirmé d'une culture repliée sur sa survivance et la menace constante de sa disparition ${ }^{45}$.

Pourtant, nombre d'expressions au sein de la culture québécoise témoignent au contraire de l'apparition de phénomènes culturels qui sont à appréhender dans un ordre sensiblement différent de celui auquel adhèrent les analyses de Dumont, et les perspectives analytiques qui en sont issues vont justement dans le sens d'une évolution très significative, qu'on peut situer entre autres en parallèle des réinterprétations de la culture de masse auxquelles nous avons fait référence ${ }^{46}$. La caractéristique essentielle de ces manifestations est qu'elles s'enracinent dans une expérience du monde au lieu de vouloir loger à l'enseigne d'une «transcendance» devenant extrêmement problématique à situer à cause du caractère trop étroit de sa définition. Ainsi, du roman à la musique, de la peinture au cinéma, de la danse à l'architecture ou à la poésie, du théâtre aux festivals, c'est tout le domaine des arts contemporains qui appelle un examen susceptible de révéler à l'interprétation la portée transcendante de ses expressions. Mais les arts ne sont pas le seul domaine à informer de la sorte la culture contemporaine, puisque le domaine des sciences ainsi que tous les horizons des pratiques de la culture où il y a sens et significations s'offrent aussi aux analyses afin de permettre la reconnaissance des processus dialectiques qui mènent les transformations actuelles des sociétés à rendre compte de leur composition participant à l'édification du monde contemporain où se

45. F. Dumont, L'avenir de la mémoire, op. cit., p. 604. On trouve ces deux attitudes exprimées ainsi: "Alors, ce n'est largement qu'un espoir que je tiens à désigner par la notion de tradition; mais c'est pour illustrer, par-delà des ruptures qui nous séparent des civilisations disparues, une continuité plus profonde. Pour indiquer, au surplus, que l'abandon des coutumes qui faisaient vivre les Anciens constitue sans doute pour nous une libération, mais qui nous contraint [sic] aussi à un devoir: assurer des assises pour l'interprétation de l'histoire et la participation politique. Sans ces conditions indispensables pour la vitalité des traditions nouvelles, c'est le pouvoir anonyme qui, succédant à la mort des coutumes, remplacera les citoyens dans la responsabilité de conférer un sens à l'histoire" (ibid., p. 618). Critiquant ailleurs les suites du projet de la Révolution tranquille, et surtout son "élite fatiguée", incapable de faire face au désarroi qui "gagne l'ensemble de notre société", Dumont avance, toujours en parlant de cette élite: "Elle n'a d'autre discours que de défendre, en quelque sorte, l'entreprise dans laquelle elle s'est engagée; elle ne représente plus, je crois, les inquiétudes, les désarrois de notre société, qui est confrontée au vide et à la menace - qu'on n'ose pas envisager en face - de sa disparition" (voir "Fernand Dumont et le Québec: un entretien avec Georges Leroux", Bulletin d'histoire politique, vol. 9, no 1, automne 2000 , p. 23). Visiblement, donc, la vitalité des nouvelles formes d'expression de la culture échappe définitivement à l'attention de Dumont, de même que les possibilités de leur interprétation.

46. Voir notamment à ce sujet $\mathrm{Y}$. Lamonde et $\mathrm{E}$. Trépanier, L'avènement de la modernité culturelle au Québec, Québec, Institut québécois de recherche sur la culture et Presses de l'université Laval, 2007 [1986]. 
trament les transfigurations de la culture. Ce sont là, en tout cas, des directions que peuvent emprunter des voies analytiques nouvelles dans l'interprétation de la culture, et que nous nous contentons d'indiquer ici, faute de pouvoir les poursuivre de manière plus étendue. Avant de conclure sur la part qui revient à la sociologie de la culture dans ce contexte, disons également que, à l'égard de la dimension proprement politique de l'analyse dumontienne que nous avons laissée volontairement de côté ici, nous ne pouvons que soumettre l'idée que c'est à partir d'une assise analytique de la culture telle que nous la percevons qu'une telle dimension pourrait être repensée, et non pas, à l'inverse, à partir d'une prescription formelle à l'égard d'une tradition culturelle écourtée de son expérience historique concrète et de ses déterminations contemporaines complètes $^{47}$. À cet égard également, la sociologie de la culture de Fernand Dumont nous apparaît devoir être critiquée en profondeur.

Nous sommes parfaitement conscients du caractère seulement partiel de la critique amorcée ici de l'œuvre de Fernand Dumont vis-à-vis des exigences de la sociologie de la culture contemporaine. Nous reconnaissons que l'approfondissement de cette critique appelle des élaborations auxquelles nous ne pouvons donner cours dans le cadre de cet article, étant donné les limites qui nous sont imparties. Toutefois, nous soulignons que, du fait de son importance, l'œuvre de Dumont appelle justement une réception qui soit à la hauteur des attentes de la réflexion contemporaine portant sur les pratiques culturelles, en sachant reconnaitre les problèmes principaux qui apparaissent dans le contexte actuel de la réflexion - et cela, avant tout, du point de vue d'une analytique de la culture prise ellemême dans un procès dialectique qui la met réflexivement en scène. Dans ce sens, les problèmes nous paraissent être principalement de trois ordres: d'abord, savoir reconnaitre que le fondement des pratiques culturelles de toute société humaine ne peut s'enraciner ailleurs que dans une dialectique de la signification qui anime toute forme symbolique, quelle qu'elle soit; ensuite, que le contexte sociohistorique qui voit apparaître et se manifester

47. Dans une de ses formulations, issue de Raisons communes (1997), Dumont parle de "nation française en Amérique" pour qualifier l'assise culturelle d'une orientation politique nationale au Québec. Formulation mystérieuse, en quelque sorte, qui va du côté de celle énoncée par Lionel Groulx dans cette tradition historienne provenant du dix-neuvième siècle. Mais que faut-il donc entendre ici par «nation française»? Toute l'ambiguiité de cette référence fait entre autres l'impasse sur les constituants autochtones, britanniques et immigrants divers, ainsi que sur les cadres territoriaux québécois, canadien et américain (au sens continental) qui ont façonné l'expérience sociohistorique concrète de la société québécoise. L'interprétation que propose Jacques Beauchemin d'une reconduction de cette formulation dans le contexte d'un projet politique spécifique (celui du souverainisme) nous paraît porteuse des mêmes problèmes que nous avons identifiés comme étant ceux d'une analytique de la culture chez Dumont (J. Beauchemin, "La communauté de culture comme fondement du sujet politique chez Fernand Dumont", Bulletin d'histoire politique, vol. 9, no 1, automne 2000, p. 29-39). 
les formes symboliques des pratiques culturelles permet de situer non seulement la localisation et la genèse précises de ces dernières, mais tout autant le mouvement de formation, de déformation et de transformation par lequel de telles in-formations traversent l'horizon de ce contexte, en fonction des possibilités de prolongements, de ruptures et de retournements qu'elles manifestent; enfin, que le contexte contemporain des manifestations de la culture, situé entre ses limites mondiales et ses enracinements locaux, nous permet avant tout de penser ces questions au Québec à l'intérieur même de ce rapport - soit dans une perspective qui parvienne à localiser des interrogations au sujet de la culture au Québec, davantage au fait qu'au sujet de la culture québécoise. De toute évidence, il ne s'agit pas ici d'une simple reformulation sémantique. Il s'agit plutôt de parvenir à savoir comment les pratiques culturelles de la société québécoise sont inscrites dans une expérience sociohistorique qui dépasse cette dernière, à la fois dans son "en deçà" (traditionnel, si l'on veut), et dans son "au-delà» (actuel et futur). En effet, ce n'est que dans sa participation active au monde que la culture, au Québec, parvient à actualiser le sens et la signification qui la caractérisent. Dans les formes spécifiques qu'elles développent, les pratiques culturelles qui ont cours ici participent d'une dynamique qui est certainement nationale, mais parce que ces dispositions dépendent à leur tour de la participation au monde social et historique prenant corps au sein d'un univers qui a avalisé cette forme typique de réalisations au travers d'un parcours dont on voit aujourd'hui assez précisément les contours - et les limites -, notamment du point de vue du dialogue des cultures qu'il implique ${ }^{48}$. Les exemples auxquels nous nous sommes brièvement référés, pour montrer comment certains blocages présents chez Fernand Dumont empêchent de telles reconnaissances, nous permettent tout autant de laisser entrevoir comment les manifestations de la culture de masse, si prégnantes dans l'univers des médias notamment, ont entre autres permis que prennent forme des pratiques culturelles spécifiques ayant pour visée d'arrimer le développement de la société québécoise au mouvement de déploiement des sociétés contemporaines, dans lesquelles les nouvelles formes émergentes d'expression médiatique prennent le relais des formes modernes de détermination des pratiques ${ }^{49}$. Ici, comme dans

48. À ce sujet, voir entre autres Y. Lamonde, Allégeances et dépendances. L'histoire d'une ambivalence identitaire, Québec, Nota Bene, 2001. Devons-nous souligner ici l'uoubli» de Lamonde à l'égard de la contribution des sociétés autochtones à la constitution identitaire du Québec, au-delà des apports des héritages français, anglais, étasuniens et catholiques qu'il relève - alors que le patronyme même de cette culture nationale est issu de ces sociétés?

49. À ce titre, et pour indiquer comment, par exemple, les «organisations médiatiques" radiophoniques et télévisuelles ont su répondre et correspondre à autre chose qu'au "bric-à-brac» de la culture contemporaine, voir notamment G. M. Nielsen, Le Canada de Radio-Canada. Sociologie critique et dialogisme culturel, Toronto, GREF, 1994, ainsi que M. Vipond, The Mass Media in Canada, Toronto, James Larimer \& Co., 1992, p. 24-46. 
toute manifestation culturelle, le "destin" à appréhender se situe justement du côté des formes symboliques qui transforment l'expression au moyen d'une matérialité susceptible de la faire reconnaître dans ses virtualités et ses dispositions propres - soit dans ce que ces formes symboliques deviennent au travers de leurs manifestations, en s'actualisant dans des réalisations grâce auxquelles elles sont reconnues. Dans l'aval des analyses à faire sur ce plan, toute une évaluation peut entreprendre de soupeser la signification politique et idéologique de telles manifestations, mais en gardant surtout à l'esprit le caractère spécifique (traditionnel, présent ou novateur) qui les fait participer de leur propre contexte sociohistorique en lui donnant une forme déterminée. En d'autres termes, ce n'est que par le biais d'une analytique des pratiques culturelles que l'on parvient à saisir la signification en mouvement qui les anime.

L'apparition de nouvelles aires de pratiques culturelles, au cours des deux derniers siècles, ainsi que leurs interrelations, couplées à une variété de nouvelles dénominations ou encore de dénominations traditionnelles servant à singulariser les parties d'un découpage du champ de la culture, ont toujours été l'objet de débats en sociologie de la culture et constituent encore aujourd'hui un projet central de théorisation. Dans le contexte contemporain, où la culture dans laquelle sont immergés les individus d'ici et d'ailleurs est devenue médiatisée, mondialisée et circulant souvent à haute vitesse, les transferts, échanges et relations entre les pratiques culturelles se sont intensifiés et métissés, et ce, à un point tel que la culture peut apparaitre comme étant "brouillée" dans ses déterminations essentielles. Mais c'est qu'elle doit être comprise davantage au travers de ces mouvements, de cette circulation, qu'à partir d'un modèle qui tient à faire tenir en place des aires de pratiques et des relations seulement stables, permanentes ou universellement fixes. Cela pose le problème réel de développer des analyses qui utilisent forcément des dénominations historiques d'aires de pratiques culturelles (culture savante, culture d'élite, culture bourgeoise, culture populaire, culture traditionnelle, culture de masse) et qui doivent intégrer des dénominations ayant émergé plus récemment, en indiquant une organisation différente du domaine de la culture (culture de consommation, sous-cultures, contre-culture, culture underground, culture virtuelle, culture mondiale, cultures du monde, etc.), mais sans toutefois que ces aires en constituent des repères théoriques absolus ou des entités discrètes et fermées. Sur ce terrain historique d'une dialectique de la culture, la sociologie doit être capable d'évaluer l'expérience du monde au creux d'expériences spécifiques et de formes culturelles déterminées, sans croire que la transcendance à l'œuvre dans les pratiques culturelles échappe à cette expérience. C'est ce que nous avons tenté de démontrer en prenant appui sur l'œuvre de Fernand Dumont, qui a contribué à intégrer le champ de la culture dans l'horizon de la sociologie au Québec. Il reste toujours à voir ce que l'on peut encore aujourd'hui en tirer. 